\title{
Managing physical risk in anorexia nervosa
}

\author{
William Rhys Jones, John F. Morgan \& Jon Arcelus
}

\begin{abstract}
SUMMARY
Eating disorders encompass physical, psychological and social pathologies that increase health risk. Anorexia nervosa has the highest mortality of any psychiatric disorder, but patients are not always managed by specialist eating disorders services and the duty of care sometimes falls to the general psychiatrist. This article is an aidememoire for assessing and managing physical risk in patients with anorexia nervosa.
\end{abstract}

\section{DECLARATION OF INTEREST}

None.

Eating disorders cause significant psychiatric morbidity and the adverse physical consequences of dieting, weight loss and purging sometimes prove fatal. Mortality rates in patients with eating disorders are high (Arcelus 2011), with anorexia nervosa having a higher standardised mortality ratio (5.86) than that of schizophrenia, bipolar affective disorder and unipolar depression. That study also found that 1 in 5 deaths in anorexia nervosa were the result of suicide. Although many patients with anorexia nervosa are treated exclusively by a specialist eating disorders team, not all patients can be managed by these services. Indeed, in a disorder that can persist for decades, some of the longer-term care may at times need to be provided by the community mental health team and general psychiatrist, who must monitor the patient's physical and mental health and try to support both patients and their families. This is alarming when one considers that many general psychiatrists report a lack of training in eating disorders and are not always confident in managing these conditions in non-specialist settings (Jones 2012a). Here, we remind the general psychiatrist of how to assess and manage physical risk in patients with anorexia nervosa.

\section{Initial assessment of physical risk}

In addition to the standard psychiatric assessment (including risk of suicide), all general psychiatrists should be competent in estimating the level of acute physical risk in patients with anorexia nervosa. The predictors of physical risk have not been fully researched. Therefore the following is only a guide to 'usual practice', and should be considered in the context of a full physical examination and applied only to adults. A screening assessment should include at least:

- body mass index (BMI) (weight/height ${ }^{2}$ )

- blood investigations (full blood count, urea and electrolytes, phosphate, glucose, creatine kinase, liver function tests)

- tests for proximal myopathy (stand-up-squat test)

- examination of blood pressure (erect and supine), pulse and core temperature

- an electrocardiogram (ECG) if the BMI is less than 16 or if drugs are prescribed that prolong the QTc interval.

The screening assessment should be completed alongside the Physical Risk in Eating Disorders Index (PREDIX) (Table 1), which categorises patients into moderate- or high-risk groups on the basis of the physical examination and laboratory investigations. Features from the history that indicate a higher level of physical risk include rapid weight loss (>1 kg/week), excessive exercise at low weight, evidence of infection, symptoms of dehydration, haematemesis, pregnancy and comorbid physical conditions. Cardiovascular signs and symptoms are particularly pertinent, as cardiac arrhythmia is an important cause of death. Urgent medical admission should be considered for patients who fall into the high-risk category. Medical admission should also be considered for patients in the moderate-risk group, especially if the level of risk is increasing. However, some patients in the moderate-risk group can often be safely managed in a specialist eating disorders unit (SEDU) or in the community if adequate services are available and accessible. Decisions regarding physical risk should also take into account the patient's capacity to consent to treatment, motivation to change and availability of local resources.

\section{Risk management and medical monitoring}

\section{Medical monitoring}

Evaluation of physical risk in anorexia nervosa should be seen as a longitudinal process, with medical monitoring a cornerstone in longer-term
William Rhys Jones is a consultant in eating disorders psychiatry at the Yorkshire Centre for Eating Disorders, Leeds. He has a wide range of interests, including eating disorders and general psychiatry. John F. Morgan is a consultant in eating disorders psychiatry and head of research at the Yorkshire Centre for Eating Disorders, Leeds, and Visiting Senior Lecturer at St George's, University of London. He chairs a national research team examining treatments and risk management. Jon Arcelus is a consultant in eating disorders psychiatry at the Leicester Eating Disorders NHS Service and a Visiting Professor at the Loughborough University Centre for Research into Eating Disorders (LUCRED). He is a full member of the Academy for Eating Disorders and an elected member of the Eating Disorders Research Society.

Correspondance Dr William Rhys Jones, Yorkshire Centre for Eating Disorders, Newsam Centre, Seacroft Hospital, York Road, Seacroft, Leeds LS14 6WB, UK. Email: wrjones@ doctors.org.uk 
TABLE 1 Physical Risk in Eating Disorders Index (PREDIX)

\begin{tabular}{|c|c|c|c|}
\hline System & Test or investigation & Moderate risk & High risk \\
\hline Nutrition & $\begin{array}{l}\text { Body mass index } \\
\text { Rate of weight loss }\end{array}$ & $\begin{array}{l}<15 \mathrm{~kg} / \mathrm{m}^{2} \\
>0.5 \mathrm{~kg} / \text { week }\end{array}$ & $\begin{array}{l}<13 \mathrm{~kg} / \mathrm{m}^{2} \\
>1 \mathrm{~kg} / \text { week }\end{array}$ \\
\hline Cardiovascular & $\begin{array}{l}\text { Blood pressure } \\
\text { Postural drop } \\
\text { Pulse rate } \\
\text { Peripheral cyanosis }\end{array}$ & $\begin{array}{l}<90 / 60 \mathrm{mmHg} \\
>10 \mathrm{mmHg} \\
<50 \mathrm{bpm}\end{array}$ & $\begin{array}{l}<80 / 50 \mathrm{mmHg} \\
>20 \mathrm{mmHg} \\
<40 \mathrm{bpm} \\
\text { Yes }\end{array}$ \\
\hline Musculoskeletal & $\begin{array}{l}\text { Unable to stand up unaided } \\
\text { (stand-up-squat testa }{ }^{a} \text { ) }\end{array}$ & Grade 2 & Grade 0-1 \\
\hline Temperature & & $<35^{\circ} \mathrm{C}$ & $<34.5^{\circ} \mathrm{C}$ \\
\hline Blood profile & $\begin{array}{l}\text { White cell count } \\
\text { Neutrophils } \\
\text { Haemoglobin } \\
\text { Platelets }\end{array}$ & $\begin{array}{l}\text { Concern if } \\
\text { outside normal } \\
\text { limits }\end{array}$ & $\begin{array}{l}<2.0 \times 109 / 1 \\
<1.0 \times 109 / 1 \\
<9.0 \mathrm{~g} / \mathrm{dl} \\
<110 \times 109 / 1\end{array}$ \\
\hline Biochemistry & $\begin{array}{l}\text { Potassium } \\
\text { Sodium } \\
\text { Phosphate }\end{array}$ & $\begin{array}{l}\text { Concern if } \\
\text { outside normal } \\
\text { limits }\end{array}$ & $\begin{array}{l}<2.5 \mathrm{mmol} / / \\
<130 \mathrm{mmol} / \mathrm{l} \\
<0.5 \mathrm{mmol} / /\end{array}$ \\
\hline Electrocardiogram & $\begin{array}{l}\text { Pulse rate } \\
\text { Corrected OT interval (QTc) } \\
\text { Arrhythmias }\end{array}$ & $<50 \mathrm{bpm}$ & $\begin{array}{l}<40 \mathrm{bpm} \\
>450 \mathrm{~ms} \\
\text { Yes }\end{array}$ \\
\hline
\end{tabular}

bpm, beats per minute.

a. The stand-up-squat test gives a clinical indication of muscle power and may be used to monitor progress. The patient either lies flat on the floor and has to sit up or sits in a chair and has to stand up, without, if possible, using their hands. Scoring: Grade 0, completely unable to rise; Grade 1, able to rise only with use of hands; Grade 2, able to rise with noticeable difficulty; Grade 3, able to rise without difficulty.

care, alongside standard psychological and social interventions. Medical monitoring should include a minimum of a BMI check, ECG and blood investigations (urea and electrolytes, liver function tests, phosphate, glucose), and efforts should always be made to engage primary care services in the monitoring process. Clear lines of responsibilities for each patient's medical monitoring should be agreed between the primary and secondary care teams. A plan of action should be agreed for implementation if physical health deteriorates. Any agreements should be developed and shared with the patient and, where appropriate, with their families and carers, and should be put in writing. The results of physical monitoring should be explained to the patient, as it may help them to accept responsibility for their treatment and may increase motivation to change. Proper integrated care coordination, such as the care programme approach (CPA), can play a significant role in managing physical risk and improving treatment adherence. Establishing a close relationship with a community liaison nurse and a dietitian from the local specialist eating disorders service (if available) can be invaluable. The frequency of medical monitoring in the community can vary from weekly to monthly and will depend on a number of factors. Patients who require more frequent (i.e. weekly) monitoring will be those who fall into the moderate-risk category in Table 1 . The frequency of monitoring can be reduced accordingly as the level of physical risk reduces. Some patients with chronic anorexia nervosa may consistently present with one or more moderate-risk indicators without necessarily indicating immediate risk. For example, some patients may tolerate BMIs of 12-14 for many years and may present with a normal biochemistry profile despite their very low weight. In these cases, medical monitoring can be more flexible (e.g. fortnightly) and adjusted according to the patient's clinical history and overall physical examination.

\section{Care planning}

Patients may present with a mixture of physical, psychological and social disabilities, and a care plan should be tailored to meet individual needs. With regard to risk management, it should show:

- the health professional(s) responsible for medical monitoring

- the frequency of medical monitoring and details of tests required

- comorbid conditions such as depression and substance misuse

- risk of suicide and self-harm

- the identified SEDU and medical ward if urgent admission is required

- the crisis BMI (e.g. <13.5) and risk indicators (including risk of suicide) that warrant urgent hospital admission and the possible use of compulsory measures.

\section{MARSIPAN and other useful resources}

The general psychiatrist should be aware of the MARSIPAN report (Royal College of Psychiatrists 2010), which provides comprehensive guidelines on the assessment and management of physical risk and advice for commissioners on required services for patients with severe anorexia nervosa. For further information on anorexia nervosa and other eating disorders, please refer to the National Institute for Health and Clinical Excellence (2004) guidelines and Jones et al (2012b).

\section{References}

Arcelus J, Mitchell AJ, Wales J (2011) Mortality rates in patients with anorexia nervosa and other eating disorders. Archives of General Psychiatry 68: 724-31

Jones WR, Saeidi S, Morgan JF (2012a) Knowledge and attitudes of psychiatrists towards eating disorders. European Eating Disorders Review 16 Jan, doi: 10.1002/erv.2155.

Jones WR, Schelhase M, Morgan JF (2012b) Eating disorders: clinical features and the role of the general psychiatrist. Advances in Psychiatric Treatment 18: 34-43.

National Institute for Health and Clinical Excellence (2004) Eating Disorders: Core Interventions in the Treatment and Management of Anorexia Nervosa, Bulimia Nervosa and Related Eating Disorders. British Psychological Society \& Gaskell.

Royal College of Psychiatrists, Royal College of Physicians (2010) MARSIPAN: Management of Really Sick Patients with Anorexia Nervosa (College Report CR162). Royal College of Psychiatrists. 